\title{
A Metalinguistic Study on the Photon Interpretation Present in Physics Textbooks Approved in PNLDEM 2015: Elements for a Symmetric Sociology of Science Education
}

\author{
Nathan Willig Lima ${ }^{\circledR}$ Brazil \\ Bruno Birkheur de Souza ${ }^{\circledR}$ Brazil \\ Fernanda Ostermann ${ }^{\circledR}$ Brazil \\ Claudio José de Holanda Cavalcanti ${ }^{\circledR}$ Brazil
}

We present a work on Symmetric Sociology on Science Education from a theoretical framework that articulates Bruno Latour's and Mikhail Bakhtin's Philosophies. We perform a metalinguistic analysis of the texts about Quantum Physics present in the Physics textbook approved by the PNLDEM 2015 in dialogue with the philosophical interpretations about the photon in scientific papers. We present the dialogic relation among the different scientific and didactic speeches, explicating the re-elaboration of meaning that exists in every text. We show that the textbook authors hybridize different visions into a particular vision, which is not in dialogue with contemporary research in most textbooks, so these narratives could not even be considered Quantum Physics (since they attribute to photons a performance with many classical aspects). Furthermore, we show that all textbooks omit the theoretical construction that encompasses the photon, following the same didactic and ideological proposal found in undergraduate textbooks, as described by Kuhn, that is, omitting controversies and pushing the establishment of a paradigm. Such didactic parallel suggests the subordination of Science Education to the Scientific Community in a sort of didactic colonialism. Even if we agreed that the goal of Science Education is to educate "little scientists" (which is not the case), there is the problem that the paradigm presented by the texts has not been hegemonic for, at least, eight decades. Finally, the developed theoretical articulation proved to be fruitful to analyze Science Education and its symmetrical relations with nature and society.

Keywords: Quantum Physics; Textbook; Latour; Bakhtin.

\section{Introduction}

Research on textbooks has grown in Brazilian academic production over the last forty years (Garcia, 2017). They embody a wide range not only of subjects (specific subjects of each discipline), but also of research problems, involving issues such as curriculum, role of textbook, epistemological visions, historiographical and conceptual errors, resources, among others. On an international scale, since the publication of The Structure of Scientific Revolutions (Kuhn, 1978), the "instruction manual" is recognized 
as an important element of scientific culture, capable of "transmitting" exemplary issues to subsequent generations of researchers and initiates them in the paradigm of their area.

The Kuhnian description regarding textbooks has "warned" Science Education researchers about the problem of "historiographical distortions", which result in the implicit defense of an epistemological view in line with the current paradigm (Brush, 1974). From such a view, many studies have been developed, contrasting the History of Science with the pseudo-stories present in textbooks (Siegel, 1979; Allchin, 2004). They show that a positivist bias is responsible for discursive variations present in books (Kincheloe, \& Tobin, 2009), such as omitting metaphysical assumptions (Silveira, 2002), overestimating the role of empirical data in constructing a theory (Silveira, \& Ostermann, 2002) and underestimating the quality of theories that have lost their hegemony in the scientific community (Piassi, Santos, Vieira, \& Ferreira, 2009).

By taking this approach, some researchers of History and Philosophy of Science (HPS) in Education, in contrast to a positivist discourse, ended, without realizing it, by reinforcing it in another aspect. They opposed naive empiricism in science, but often adopted naive historiographical empiricism. Namely, for them, books adopt a pseudohistory; but they, the researchers, would be able to present the True History of Science, accessed immediately and objectively through primary sources.

Bruno Latour (Latour, \& Woolgar, 1988) reported a similar problem in the area of Science Studies: the Strong Sociology Program (Bloor, 1982) was constructivist for the nature but objectivist for the society (Latour, 2013). In opposition to this view, Latour adhered to the Sociology of Translation (Callon, 1986) (also called Symmetric Sociology) as an alternative that did not fall back on the asymmetry of the Strong Program, describing the interaction between humans and nonhumans by translation relations between actants.

Our objective is to analyze the construction of narratives about the photon in books approved by the National Plan of Textbooks for High School (PNLDEM in Brazil) in 2015 (Ministério da Educação, 2014), trying not to fall into the reductionist view that there is an objective history to contrast with history from the book. This means, in short, that we oppose the dichotomy of history versus pseudo-history. In making such an approach, however, we do not fall back on a relativistic proposition. Thus, we intend to present a metalinguistic study based on Bakhtin's Philosophy of Language, in order to provide subsidies for the proposition of a Symmetric Sociological Program in Science Education

By recognizing the textual nature ${ }^{1}$ (Wertsch, 2004) of each scientific article and chapter of the textbook, it is possible to infer that they will always "distort" the original

\footnotetext{
1 Wertsch (2004) adopts a wider notion of text, as a discursive manifestation (that can be oral or written). These texts mediate what the author calls collective memory or, as the author highlights, collective remembering. According to this perspective, remembering (or memory) is not an action realized by an isolated individual, but actions mediated by socially shared textual resources. These resources can be inserted in a wider spatial and temporal context.
} 
story. This is not done because there is a historiographical neglect, but because it is from the very nature of verbal communication processes to reexpress previous discourses, re-elaborating and re-emphasizing them (Bakhtin, 2016). Even if one wanted, his interpretation of Einstein's 1905 article would never be "Einstein's View of 1905", because when Einstein is spoken, the speaker's voice ${ }^{2}$ hybridizes $^{3}$ with Einstein's. Thus, a historical narrative cannot be understood as a mirror of historical reality, but as a text about history, that, in dialogue with other texts, translates (Latour, 1999) the story for the reader. Such a translation implies variations not only on social history itself, but also on nature, since these two elements cannot be dissociated (Latour, 1999).

From this conception, it is possible to show that the processes of re-elaboration of a given scientific production, by stressing and varying meanings of concepts and equations, also appear in scientific articles and are not a privilege of textbooks. Namely, both the meaning and history of the photon are multiple not only in scientific but also in didactic production.

In order to explain these relations, we first present a brief history of the photon, based on bibliography of Max Jammer (1974), through which we highlight the discursive processes of re-elaboration of meaning in scientific articles, which are interpreted as processes of translation (Callon, 1986; Latour, 1999). Our narrative discusses how the ontological and epistemological view on the photon varies through history and show that the re-signification of scientific articles is not a privilege of textbooks, but an element present in every single discursive process. From this perspective, our own narrative is not a mirror of historical reality, but a possible construction that dialogues with scientific articles and textbooks symmetrically.

The choice of this theme is due mainly to the relevance that literature has attributed to the introduction of Quantum Physics in High School (Ostermann, \& Moreira, 2000; Silva, \& Almeida, 2011) and also because this subject is introduced in textbooks of the PNLDEM in a chronological approach (Lima, Ostermann, \& Cavalcanti, 2017), which makes it a propitious subject for a research that seeks to analyze historiographical questions from Symmetric Sociology $y^{4}$.

According to the literature about Philosophy of Quantum Physics (Bunge, 2013, Jammer, 1974, Pessoa Jr., 2003), the interpretation of a theory corresponds to a set of theses that is added to the minimal formalism of a scientific theory, and that in no way affects the observational predictions of the theory. For example, the book "Concepts

2 Voice is the speaking personality, the speaking consciousness (Wertsch, 1992). The voice always has will or desire, its own tone and overtone (Bakhtin, 198, p. 434).

3 Hybridization is a mixture, inside a single concrete utterance, of two or more linguistic consciousness, frequently widely separate in social space and time.

4 Most Physics textbooks do not deal with Science under a chronological perspective, but a postulational one. In such cases, the history is place at a secondary plane, and a historiographical analysis of the textbook theme is impaired. In the case of Quantum Physics, however, the textbook structure follow the original papers history, hybridizing to teach Physics with teaching Physics History. By investigating the sociological aspects surrounded in this presentation, we can, at the same time, discuss Physics and its history, crossing the borders between nature and society, as it is expected from a latourian research. 
of Quantum Physics" (Persona Jr., 2003) presents different mental experiments with the Mach-Zehnder interferometer to explore wave-particle duality and the different interpretations it raises. Based on the work of Jammer (1974), Pessoa Jr. (2003) divides the interpretations of the photon into four groups (corpuscular, wave, realistic dualist and Copenhagen interpretation). Although both the mathematical formalism used and the experiment are the same, these four interpretations differ from one another regarding the explanation of what is being observed and described mathematically.

Such a definition is necessary so that we can specify that the scope of the research encompasses the interpretations of the theory, that is, we are interested in analyzing how the textbooks state the theory; with which worldview (ontological and epistemological) they align ${ }^{5}$. Specifically, our work answers the following questions: How do textbooks talk about the photon? To what philosophical interpretations do the textbooks adhere? What are the relationships between the textbook exposition and the narrative of the original articles? What are the didactic implications that can be inferred from this analysis?

\section{Theoretical-Methodological Framework}

The present work deals with questions related to the nature of Science and Science Education through the analysis of scientific and didactic texts. It is therefore necessary to use a theoretical framework that addresses not only epistemological and sociological questions, but also the nature and the role of language. For this reason, we propose an articulation of concepts from Symmetric Sociology by Bruno Latour and from Philosophy of Language by Mikhail Bakhtin. While Latour has his work dedicated to studying scientific practice (approaching ontological, epistemological, and sociological problems), Bakhtin presents a deep and complex Philosophy of Language, whose scope transcends the limits of language itself, which often makes his work to be considered about metalinguistics ${ }^{6}$. We present, in this section, the key elements from the philosophies of these two authors.

\footnotetext{
5 It is possible to find similar studies to undergraduate textbooks, in relation to the photon interpretation (Lima, Antunes, Ostermann, \& Cavalcanti., 2017b) as well as to historiographic issues (Lima, Antunes, Ostermann, \& Cavalcanti., 2017a, 2017c).

6 Latour (2013) criticizes discursive studies or, as he call them, “The Empire of Signs" (Latour, 2013, p. 63), because they dissolve the ontological poles of nature and society, reducing reality to discursive effects. Bakhtin, despite of being a philosopher of language, does not reduce reality to language. On the contrary, the materiality of signs and, therefore, of all ideological construction, appears in one of the seminal works of Bakhtin's Circle (Bakhtin, 2006). Furthermore, the heart of his metalinguistic is the possibility of articulating the verbal speech with society and culture (external but still interdependent to the speech) (Bakhtin, 2016, 2017). Thus, the critics made by Latour cannot be directed towards Bakhtin's work. Moreover, even though Latour criticize the semiotic tradition of the modern world, Latour himself take hand of semiotic and discursive studies in different works. We can mention, for example, a study on scientific paper references as a social shielding of the research work. (Latour, 2011), a typology of utterances that are used in the process of stabilization of a scientific fact (Latour \& Woolgar, 1997), a study on the interrelations between signs and technologies (Latour, 1999), a semiotic study about Albert Einstein's book (Latour, 1988) and a study about rhetoric in scientific papers (Latour, \& Fabbri, 1977). Such semiotic elements in Latour's work, however, are dispersed and disconnected in such a way that it is not possible to determine completely his conception of language. This justifies the necessity of bringing elements of Bakhtin's Philosophy of Language to the present work.
} 


\section{Symmetrical Sociology by Bruno Latour: Actants, Performances and Translation}

Bruno Latour's proposal stands out because it opposes what the author calls a modern description of reality, which separates nature and society into independent ontological poles, being language the possible link between them (without hybridizing with them though) (Latour, 2013). The Symmetric Sociology of Latour, on the other hand, assumes that neither nature nor society are objective, finished, or independent realities; but that, at all times, nature and society are stabilized by the practice of different human and non-human agents (Latour, 2013).

Instead of thinking that in nature and in society there are previously existing elements, Latour proposes the notion of actants, which do not exist as objective entities, but are defined and stabilized by the relations with the other actants and by the responses they provoke in their interactions, what we call performances (Latour, 1999). By using this term, we do not distinguish between humans and nonhumans, avoiding the fragmentation proposed by later modern studies.

Latour (1999) tells, for example, how yeast (an actant) can come into existence from the association of Pasteur (another actant) with lactic acid (another actant). Yeast had not existed before these two actants associated themselves. Only through the relationship established by Pasteur with lactic acid did the ferment begin to present different responses in laboratory tests (their performances). Pasteur never had access to yeast itself, but to its performances, and there would be nothing to define the yeast without them. Moreover, as the relationships and performances of yeast change, it changes itself. In the end, yeast is the label used to designate the set of performances and actants that are associated in a single network.

Since the essence ${ }^{7}$ (objective and autonomous) of the yeast is denied in favor of its network of associations and performances, which is always mutable and contingent, the concept of truth becomes diluted. For a modern, the concept of yeast (element of language) would be true if it corresponded to a "real" yeast (element of nature) (Latour, 1999). However, we never have access to yeast but to its performances and its network of actants. That is, we can never be able to confront the concept of yeast against the yeast from the natural world. Such a finding makes it impossible to build up any conception of truth by correspondence and suggests an antiplatonic bias ${ }^{8}$ in Latourian philosophy.

If we cannot validate scientific practice as a confrontation between language and matter (Latour, 1999), then must we assume that scientific production is of the same

\footnotetext{
7 The philosophical discussion about existence and essence goes back to Aristotle (Nelson, 2012), to whom both were inseparable. Saint Thomas Aquinas, on the other hand, stated that essence precedes existence, because it is possible to conceive the essence of an entity that does not exist. Sartre, differently, derives from the inexistence of God that, at least, humans have their existence before their essence, since they were not intellectually conceived before existing (Sartre, 2007). By extending human properties to nonhumans, Latour applies Sartre's existentialist principle (the existence precedes the essence) to the scientific facts (Latour, 2013).

8 Plato distinguished the world of Ideas from our material reality. A detailed vision of Latour's opposition to platonic philosophic can be found in "The Invention of ScienceWars" (Latour, 1999, p.216).
} 
nature as any other literary work? Namely, does the impossibility of conceiving truth by correspondence tests force us to set a relativistic stance regarding scientific knowledge? Latour's answer is no for both questions (Latour, 1999). Although there is no one-to-one ontological correspondence between language and nature, scientific practice takes place as a chain of translations, whose stability is what guarantees the validity of a practice or an actant.

Translation, in this context, "does not mean a shift from one vocabulary to another, from one French word to one English word, for instance, as if the two languages existed independently. [It is] used to mean displacement, drift, invention, mediation, the creation of a link that did not exist before and that to some degree modifies the original two" (Latour, 1999, p.179).

Latour exemplifies such a concept in the case of a person carrying a weapon. A supporter of a purely sociological (and naive) view would say, "guns don't kill people, people kill people." - that is, the person acts, the gun is only an instrument of human action without any agency. On the other hand, an extremely materialistic (equally naive) position, for example, would place the person as subservient to the gun: we become instruments of instrumentality (Latour, 1999). Latour's view is neither of these two positions though. A gun cannot kill by itself. A person (without a gun) may feel like hurting another person, but not being able to kill him. However, when the person with the will to hurt has a weapon in his hand, uncertainty arises regarding the possible action they can take. In isolation, none of the actants had the kill performance available. The person-gun actant, however, has this possibility readily available. Such a process of uncertainty about goals and performances is what is called translation. It is a concept used to describe the association between any two actants (be they human or nonhuman). In the case of the weapon, the nature of the translation is non-verbal, although there may be a case in which the translation process also involves semiotic elements.

This is exactly what happens in the case of scientific practice (Latour, 1999). At each stage of such practice, the studied actant functions as a sign of the previous step and as raw material for the next step (i.e. it is a hybrid of matter and sign). Such a hybrid, at each stage, is associated with other actants, resulting in the translation of a new hybrid with new performances. Although the actant formed in one step does not mirror the previous one, there is a relationship between them. This is represented in Figure 1.

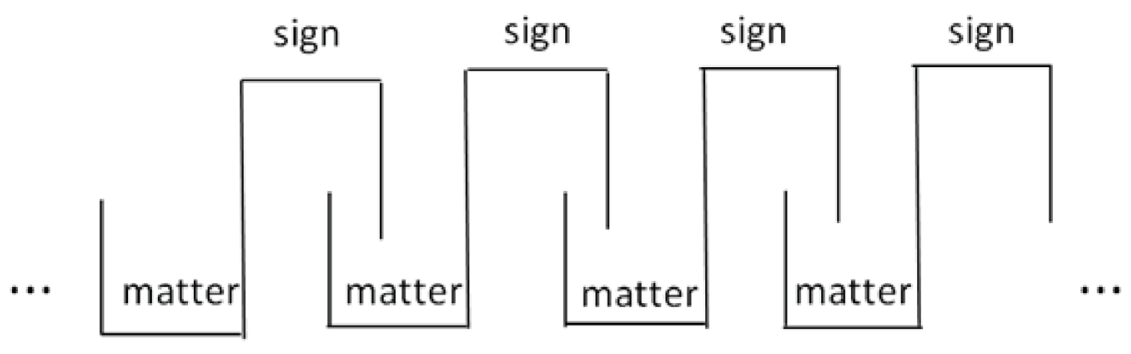

Figure 1. Chain of translations in scientific practices (Figure adapted from Latour, 1999, p. 70) 
Taking back the example of yeast, with each new laboratory test, Pasteur translates the results of experiments to the same extent that the devices translate Pasteur's intentions (symmetrically). With each new experiment, new performances translate a new yeast. Thus, although we cannot confront a theoretical yeast (belonging to language) with the yeast from the real world (belonging to nature), we can investigate the whole translation chain and trace what associations were made and how each performance was mobilized towards the stabilization of an actant. Thus, what validates the scientific practice is not the confrontation between the natural and social world, but the stability of the entire translation chain (Latour, 1999). If any of the translations made are inconsistent with the rest of the chain, the whole process may be compromised.

Latour's conception, therefore, cannot be considered relativistic, since it is possible to evaluate the reality of a certain actant by the extension and the stability of the chain that it mobilizes. The more extensive and stable the chain of translations is, the more real that actant becomes (Latour, 1999). One of the goals of Symmetric Sociology is to investigate the chain of translations, tracing the relationships between all involved actants, whether it is human or non-human, crossing the boundaries between nature, language and society as often as necessary.

At the end of a long chain of translations in a scientific practice, there is the production of a scientific article. In this sense, the article is another link in the chain of translations carried out by the scientist: from such text, new texts can be produced, working as a sequence in the chain mentioned as well, since each new text translates the previous texts and so on.

A text in History of Science, for example, will never be a mirror of "the history of the real science," just as the "concept of yeast" cannot be a mirror of "real yeast." The history book translates the original articles, just as each stage of the scientific process translates the previous actant. In this work, we present an analysis of how scientific articles translate other scientific articles and how textbooks translate scientific articles, showing the uncertainties and the variations that arise with each new stage. As the nature of these translations is intrinsically discursive, we adopt a theoretical framework capable of deepening this question: Bakhtin's Philosophy of Language $(1997,2016,2017)$.

\section{Bakhtin's Philosophy of Language: Signs and Dialogism}

One of the characteristics that distinguishes Bakhtin's intellectual production from the other aspects of the discourse of his time is his proposal of a materialist theory about ideological construction (any knowledge that is either scientific, religious, moral, etc.), namely, a theory that does not distinguish ideological construction from matter. The Platonic view that there is a world of ideas separated from the material world is made impossible by Bakhtin insofar as "everything is a sign. Without signs, there is no ideology". (Bakhtin, 2006, p. 29), and

"signs also are particular, material things; [...] as we have seen, any item of nature, technology, or consumption can become a sign, acquiring in the process a meaning that 
goes beyond its given particularity. A sign does not simply exist as a part of a reality - it reflects and refracts another reality." (Bakhtin, 2006, p. 30).

In this sense, ideological constructions are only possible from the sign, which, for Bakhtin, is a natural (material) body whose meaning goes beyond its own particularities, reflecting and refracting another reality. A metallic pendant in the shape of a sixpointed star, for example, is both a natural body and a sign, as it refers to something external to the star itself, in this case, Judaism. The relationship between the six-pointed star and Judaism, however, cannot be considered unequivocal. Not all people have the same relationship either with the sign or with the reality to which it refers. There is an uncertainty involved in this relationship. Thus, the sign cannot be considered to reflect (correspond) univocally to reality, but to "distort" (refract) it. We observe that this notion meets Latour's worldview, to which sign and matter are inseparable and for which the relation between a sign and what it means always involves the existence of variations and uncertainties.

Another important point that emphasizes the Bakhtinian work in relation to the other aspects of the discourse is that Bakhtin is not concerned with studying the language only by itself (a predominant perspective in Saussure's Linguistics): he focuses on the concrete acts of communication. In this perspective, verbal communication consists of a verbal part itself, but also an extraverbal part, not expressed but implied (Voloshinov, 1981), for which knowledge is an indispensable condition for its interpretation.

If we do not consider the extraverbal dimension, the verbal dimension cannot be understood. For example, a verbal expression such as "What a pity!" may take different meanings depending on the situation in which it is expressed, and may indicate sadness (after hearing a sad report) or irony (after hearing a supposedly sad story). The analysis of discourse, therefore, inevitably goes through a recognition of the extraverbal context. Such a context can be thought of in a more direct sense (as the context in which communication is occurring), especially when speaking of an act of oral communication. But as in the case of the present study, when we interpret texts (Wertsch, 2004), the context is given by a set of other texts that dialogue with each other (Bakhtin, 2017). To interpret the meaning of a text, we can first investigate to what genre of discourse it belongs and what is its relation to the sphere of human action in which it is performed; but also with what other texts (of the same genre of discourse or not) it dialogues with.

Each field of human action, depending on its objectives and conditions, deals with relatively stable discursive structures, which we call the discourse genre. We know, for example, that the genre of scientific articles in Physics accepts texts with a relatively determined theme, structure and style. If someone submits a text with a different theme, structure, or style than is expected, the article will probably not be accepted. Therefore, before producing an article, the announcer already knows what possible themes, structures and styles may be more appropriate. In a discursive analysis, one can do the reverse process: we identify the theme, the structure and the style of

9 Style refers to lexical, gramatical and phraseological choices made by the author (Bakhtin, 2016) 
the text and, from this, we infer characteristics of the field of action in which the text was presented. For example, from the style of the discourse mentioned, one can infer whether a given context has more authoritarian (when the limits of the discourse quoted are well demarcated) or liberal (when the discourse quoted dissolves in the discourse of the speaker) tendencies. (Bakhtin, 2006).

At the same time that the author organizes their text thinking about the field of activity in which they are inserted, they do not construct it from an absolute void, but do so in dialogism with previous texts that they have already witnessed.

Moreover, any speaker is himself a respondent to a greater or lesser degree. He is not, after all, the first speaker, the one who disturbs the eternal silence of the universe. And he presupposes not only the existence of the language system he is using, but also the existence of preceding utterances-his own and 6shs1s'-with which his given utterance enters into one kind of relation or another (builds on them, polemicizes with them, or simply presumes that they are already known to the listener). Any utterance is a link in a very complexly organized chain of other utterances. (Bakhtin, 2016, p.26).

Thus, each text only exists in its dialogical relationship with previous texts and in a way to anticipate the response that it hopes to cause in its field of action. Interpreting a text, therefore, requires picturing these dialogical relations, bringing the text closer to other texts (Bakhtin, 2017), a potentially infinite work: "The object of humanities is the expressive and speaking being. This being never coincides with itself and therefore is inexhaustible in its meaning and significance." (Bakhtin, 2017, p. 59). This, therefore, explains another path of discourse analysis for Bakhtin. Someone who has studied Epistemology, for example, can read a scientific text and polemicize it from its previous readings by agreeing or disagreeing with different perspectives that the scientific text can present, by doubting them. In this process, the reader is constructing an interpretation about the text, that is, creating a new meaning for something that is materially limited (Bakhtin, 2017). Every reading, every interpretation in this sense is active, is pregnant with the answer (Bakhtin, 2016). In addition to the stylistic analysis, which allows us to understand the relation of the text to its field of action, interpreting a text is to bring it closer to other texts, explaining the dialogical relations between them.

\section{Methodology}

A complete overlap between the philosophies of Bakhtin and Latour cannot be an expectation. As we have already mentioned, while Latour is concerned with describing scientific practice, Bakhtin raises his conception of language from literary studies. Nevertheless, elements of the works of both authors point in the same direction. Both have an anti-platonic philosophy, merging the signs with matter. In such a conception, the sign relates to reality in an uncertain and imprecise way, reflecting it and refracting it (in Bakhtinian terms) or translating it (in Latouran terms). Still, Latour's proposal is to study a certain practice without fragmenting nature, society and language, while Bakhtinian metalinguistics allows us, by analyzing language, to talk about extralinguistic 
elements. Such tangencies allow us to explore the discourse of textbooks, investigating how they dialogue and translate scientific articles and what implications this brings to both nature and society.

In this work, the object of study are the Quantum Physics chapters of the books approved by PNLD/EM in 2015. We want to understand how each text translates the interpretations of the photon presented in the original articles of Quantum Physics. When the author of the textbook talks about the photon, a correspondence between his vision and that of the original articles cannot be expected, but it is natural that there are translations of objectives, of worldviews (ontological and epistemological) and of language. We want to know what translations are and how they occur. What are the dialogical relationships between all these texts?

What we are doing, therefore, is to interpret the original articles and to interpret the textbooks as well. This article is also a text, subject to all the characteristics and conditions discussed above. This means that our vision is not Truth, but it is an (interpretative) account of articles and textbooks. In summary, three aspects of this work should be taken into account:

1. The method of analysis of this article can be classified, in general terms, as an interpretation (Bakhtin, 2017); we are interpreting texts just as Bakhtin did as well (Bakhtin, 1984a, 1984b). Interpretation is a construction. That is, although the text is limited (as it is set of characters on a paper), its senses are potentially infinite (Bakhtin, 2017). The meaning given to the text does not depend only on the text (verbal part), but on the situation in which the text is read and, for the most part, on the knowledge of other texts with which the reader has already had contact (Voloshinov, 1930). Therefore, Bakhtin states that the process of interpretation involves the encounter of two consciousnesses (Bakhtin, 2017). Interpretation as a method of analysis consists precisely in exploiting this active reading, which constructs dialogic relations between different texts.

2. Since there are potentially infinite texts outside the text of analysis, there are potentially endless interpretations of each text. All we have to offer is a possible interpretation. The fact that there are potentially infinite interpretations of a text does not imply, however, that all of them are equipollent. This article is a translation, and, as such, it is also part of a translation chain. We must seek, in a metalinguistic analysis, to be consistent with the chain to which we belong. If we use ideas that are inconsistent with the theoretical framework or with the texts studied, the translation may be compromised.

3. It is necessary to limit the scope of texts that we intend to use to interpret the texts in question (the context). In the case of this work, we want to analyze the texts of the books in dialogue with the interpretations of Quantum Physics. Therefore, in the next section, we present a possible history of photon interpretations. Once this discursive context - or set of contexts - is 
established (Latour, 1988), we can read the texts of the textbooks and perceive the dialogical relations between them, that is, how they translate, transmit, reexpress, stress, omit, modify the original texts. In Figure 2, we present a diagram that synthesizes the proposal of this research.

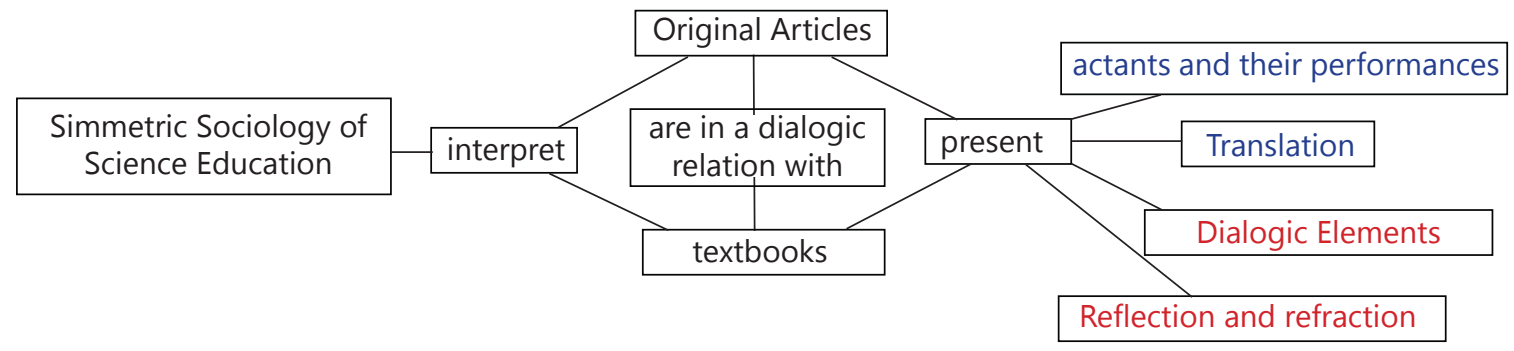

Figure 2. General outline of the research. The terms in red come from Bakhtin's Philosophy of Language and the blue terms from Latour's Science Studies

Our proposal of a symmetrical sociology study involves the interpretation of texts. In the case of this work, the research objects are the texts on Quantum Physics present in the textbooks of Physics approved in PNLDEM 2015 and the original articles of Quantum Physics (belong to different genres of discourse). All texts speak about actants and their performances and present processes of translation and dialogism. The analysis consists of tracing and describing these processes.

We have selected the 14 textbooks of physics approved in PNLD/EM 2015 and identified the specific chapter on Quantum Physics (or Modern Physics) in the $3^{\text {rd }}$ volume of each collection. Before starting a detailed interpretation of the texts, a first reading of the works is recommended, so that we have a clearer notion of the texts and with which other texts they dialogue (Veneu et al., 2015). In this stage of the research, one can, for example, sort texts into different categories depending on their stylistic likeness. After that, the interpretation of each text is then carried out in depth.

\section{A Possible History of the Photon - Philosophical Interpretations as Translation ${ }^{10}$}

The first record of a birth of a photon ${ }^{11}$ in the twentieth century did not happen in a laboratory or during any empirical activity. The photon was not, in its genesis, detected explicitly in any measuring instrument. Its articulation in the world arises by the theoretical comparison of the entropy variation of two different actants (ideal gas and radiation) in a scientific paper by Albert Einstein (1905).

Einstein's article reflects the consequences of the theories of the time and from

10 The objective of this section is to present to the reader a possible interpretation of photon history making explicit the process of translation existent in academic productions as well as present the relation between the multiple photons of history. Our goal is not to present the most complete or accurate history of photon, but to evidence that, from historiographical primary data, it is possible to have multiplicity of meaning. The history presented interprets Jammer (1974)'s and Pessoa Jr. (2003)'s presentation.

11 To Latour, in the moment that the sociotecnic network is articulated, the photon is constructed as a real entity and not a simple concept without any reality. 
previous experimental results. He did not create these theories and experiments: they existed already. Einstein tells us what the experiments "want" to say, just as a senator, in speaking, expresses the voice of the people he represents. Einstein demonstrates that the entropy of monochromatic electromagnetic radiation varies according to the volume in the same way that the entropy of an ideal gas varies. In fact, he states much more than that (just as a senator can state much more than the people would like him to speak): he states that electromagnetic radiation is analogous to an ideal gas. It arises, in Einstein's words, something that the theories of the time, alone, could not say.

In this sense, the author of the article is Einstein, but the author of the concept photon is not only Einstein. It is also Boltzmann's Statistical Physics, Thermodynamics, ideal gases, Photoelectric Effect, Thermoluminescence, ionized gases. Without Einstein, these actants would not tell us anything about the photon, because they are mute; but without them, Einstein could not tell us anything either. In this case, humans and nonhumans meditate on one another to produce a new actant. In this translation, there is more than the speech itself of the facts (the facts do not speak for themselves). Einstein's voice overlaps with that of objects. The great innovation of Einstein is precisely the interpretation he offers for the equation that relates energy and frequency $(\mathrm{E}=\mathrm{hf})$. It is precisely the translation of Einstein what traditionally marks the beginning of twentieth-century physics (Greenstein, \& Zajonc, 1997).

Subsequent articles on the photon (at that time still called quantum) speak of the performance of this actant and its association with different actants. Until the second decade of the twentieth century, corpuscular behavior was all the performance reported in the photon narratives (Martins, \& Rosa, 2014); therefore, corpuscular performance defined its essence. Arthur Compton, for example, chronicles the collisions between photons and electrons (Compton, 1923). Does his photon, however, have the exact same performance as Einstein's photon? Not really! Compton's photon transfers momentum ${ }^{12}$, which the quantum of 1905 did not. Does that mean that the Compton photon and Einstein's photon have no relation at all? Neither. Both Einstein's and Compton's photons store a translation relationship among themselves, since they are two hybrid actants of the same chain of transformations (Figure 1). This translation relationship between the two photons is reflected in the texts insofar as the narrative on Compton's photon reflects Einstein's photon, - for both are corpuscles -, but refracts it as it presents a new performance - the transfer of momentum.

In 1922, De Broglie (1922), using theoretical resources, gives way to the chain of translations of corpuscular photons, endowing them not only with momentum, but also with mass. These new actants would travel at a speed slightly below the speed limit set by the theory of relativity and, in the frame of reference itself, would be identical. In 1923, De Broglie (1923) proposed a new vision, suggesting a relativistic theory for all particles (including photons) by associating them with a group of waves, whose phase

12 Stark was the first to attribute momentum to the photon, what was considered a great mistake by Einstein (Martins, \& Rosa, 2014). 
velocity would be superior to the speed of light and whose group velocity would be less than the speed of light and identical to that of the particle. This is the first truly dual proposition (Martins, \& Rosa, 2014), as, until then, Einstein had proposed the quantum individually as a corpuscular entity, and radiation (macroscopic scale) would have wave properties.

This favorable scenario for the stabilization of the translation chain of photon, whether of a corpuscular or dual nature, however, changes with Schrödinger's quantum physics proposal and its main actant: the wave function ${ }^{13}$ (Schrodinger, 1928). As an atom emits electromagnetic radiation whose energy equals the difference of the two eigenvalues associated with energy self-states, Schrödinger translated his wave function as the very nature of electromagnetic radiation (Jammer, 1974), then he was able to translate the Stark Effect and the Zeeman Effect understanding electromagnetic radiation as wave (not as particle). The identification of the wave function as proposed by Schrödinger, however, necessarily implies the destabilization of the photon chain.

To deal with the particularities of radiation, Schrödinger proposes the concept of wave packet ${ }^{14}$. In addition, Schrödinger contributed to the destabilization of the corpuscular chain of radiation, explaining the Compton Effect with a semiclassical model with continuous radiation (Schrodinger, 1927; Greenstein, \& Zajonc, 1997). Following Jammer (1974), Schrödinger's proposal, however, had serious problems: 1) the wave propagates in phase space and not in geometric space; 2) the wave is complex; 3) the wave passes through discontinuous and abrupt changes in measurement processes; 4) wave behavior depends on the base used in the Hilbert Space.

Also in 1926, Born proposes his translation of Schrödinger's Equation (Born, 1926) for quantum objects (Jammer, 1974). By understanding them as particles, the wave function would express our knowledge about their position over time. According to Born, the square module of the wave function provides the probability density of the particle. In contrast to all that had been presented, Born restated Schrödinger's equation by introducing an idealistic worldview in that it attributes to a physical equation information about our knowledge and not about physical reality.

Born claims to have used the field idea that guides the photons used by Einstein in 1909 (Jammer, 1974); but Einstein had not attributed such meaning to his result, which is another example of a refraction of a text ${ }^{15}$. Still, Born uses Schrödinger's formalism

13 The interpretations of the wave function were proposed, traditionally, in the context of non relativistic quantum physics, which, in principle, would not encompass photons. However, there are recent proposals of developing a wavefunction fo the photon (Bialynicki-Birula, 1994, 1996) - which allows for the extension of interpretations. Furthermore, despite of not dealing with photons formally, the interpretation of the wave function is historically related to the electromagnetic field in works written by Schrodinger and Born (as we will discuss). Such relation is so intimate that Pessoa Jr. (2003) uses these interpretations to talk about photon indistinctively.

14 The wave function of a particle can be described adjusting the coefficients of a Fourier series. In this case, the particlelike behavior is reduced from an onthological status to a mere particular case of a set of possible configurations of the wave function.

15 In this process of refraction, it is possible to perceive how the scientific progress happens despite of the contradictions that it can bring to reasoning, which remembers Feyerabend's contrainduction (Feyerabend, 2011). Born is inspired by the notion of a field that guides photons proposed by Einstein, in a relativistic case, to interpret a non-relativistic equation. 
without adhering to its interpretation. In short, he translates Einstein's ideas and Schrödinger's formalism into a new view, hybridizing and refracting them: the motion of the particle is probabilistic, with the probability something that obeys a deterministic equation (the evolution of the wave function is deterministic and can be determined through Schrödinger equation in the non-relativistic case). Quantum objects get a new articulation: if the wave function represents our knowledge about the particle, its collapse represents a sudden change in our knowledge. However, this is difficult to articulate with double-slit experiments whose results seem to be more easily articulated with a wave notion as something that does not depend only on our knowledge (Jammer, 1974).

In 1927, the refraction and the reflection of previous discourses led to the proposition of another positivist synthesis, based on the concept of Complementarity (Bohr, 1928). For Bohr, reality has two frames of explanation (the corpuscular or the undulatory). Depending on the experimental arrangement, one of these frames is the most appropriate (Pessoa Jr., 2003). This position, which features a positivist and antirealist bias, is for Bohr a characteristic of reality itself and not only of Quantum Physics, in a way that can be perceived in various spheres of human knowledge. Other thinkers opposed Bohr's positivist view, articulating, once again, quantum objects as particles, especially in the context of statistical interpretation - with different refractions of Born's proposal. We can include in this group the proposals of Popper (1957) and Ballentine (1970).

This short history of philosophical interpretations of the photon, which mixes with the history of wave function and other quantum objects, shows us at least two fundamental elements about scientific knowledge. The first one is that it is not possible to find The Quantum Physics or The photon. When someone talks about photon, they need to mention what is their interpretation about it, or rather, what is the translation of both formalism and experiments they are doing. There is no single view, no scientific view, against which pseudo-scientific visions are established. What we usually call quantum physics is an extremely heterogeneous group of translations that are articulated in texts in dialogical articulation (some in agreement, others in opposition, and others in dialectical synthesis) and which communicate through reflection and refraction processes. The second element, which is a consequence of the first one, is the notion that no vision is ultimately innovative. It will always place itself in dialogue with previous texts (either confirming, denying, or proposing a synthesis) - what we call a reflective dimension of the discourse. On the other hand, no vision is a copy of previous vision; they always translate earlier visions add previously unexplored aspects - what we call the refractive dimension of discourse.

\section{Quantum Physics in Textbooks}

In making a first reading of the selected textbooks, a step discussed in the Methodology, we identified that the fourteen books could be arranged in three distinct categories according to their relation to the Philosophical Interpretations of Photon. 
Since the textbooks of each category are very similar, we chose to present, in the metalinguistic analysis, one example of each group. The three categories are presented below as well as the works arranged in each one of them:

1. The textbook does not explicitly recognize the existence of different interpretations and does not adhere to a specific interpretation. Eleven books were put into this category: Yamamoto e Fuke (2013), Guimarães et al (2013), Barreto e Xavier (2013), Luz e Álvares (2013), Bonjorno et al. (2013), Gonçalves Filho e Toscano (2013), Doca, Bôas e Biscuola (2013), Menezes et al (2013), Stefanovits (2013), Sant'Anna et al. (2013) e Torres et al. (2013).

2. The textbook explicitly recognizes the existence of different interpretations. Two books were put into this category: Artuso e Wublewski (2013), Oliveira et al. (2013).

3. The textbook adheres to a specific interpretation and argues it is the only possibility. Only Gaspar (2013) was put into this category.

The translation between the didactic textbook and the scientific paper thus appears as a typical issue of Bakhtin's Philosophy of Language: the issue of quoted discourse (Bakhtin, 2006). Bakhtin's literary analysis led him to conclude that the way in which discourse is quoted in the text (i.e. the style of writing, involving grammatical and phraseological choices) is intimately linked with the author's worldview. As text is always constructed in relation to other texts, all textbooks relate dialogically to the original articles, but some explain this dialogic relationship while others omit it. Through Bakhtinian analysis, we can infer the epistemological and didactic implications of each option.

\section{Texts that do not explicitly recognize the existence of different interpretations and do not adhere to a specific interpretation}

In the first group, in which most of the physics textbooks approved by PNLD/ EM 2015 were put, there are texts that do not explicitly discuss the existence of different interpretations of the photon. This does not mean that they do not adopt interpretations, but that the discourse quoted has its boundaries diluted throughout the discourse (Bakhtin, 2006). We chose to present the work of Bonjorno et al. (2013), as this was the most widely distributed book in public schools in Brazil according to the PNLD/EM website.

The story told by Bonjorno et al. (2013) begins with Planck:

In other words, according to Planck, the vibrating oscillators in the frequency $f$ emit energy $E$ in discrete or quantized quantities. The minimum amount of energy emitted, that is, the quantum, would be a $h f$ energy package. The "energy packets" could assume values given by $E=n h f$ (Bonjorno et al., 2013, p. 244).

According to Bakhtin, author's grammatical choices are clues to his worldview, so that an author's style cannot be analyzed separately from the theme (Bakhtin, 2016). In 
this passage, the author uses modal sentences ("would be", "could"), giving a very subtle evidence that what you are talking about will change later. Namely, even though they reflect Planck's original conception, the verbal form that introduces this conception weakens Planck's voice, working, in this case, as a modulator of the intensity of what is meant. In addition, the authors do not explain how Planck came to his ideas; they translation involves a simple statement about what Planck got. Thus, the translation of the original article by the textbook involves the erasing of Planck's theoretical construction and the propagation of a single idea to the detriment of the whole work. Planck's entire construction is summarized in a few lines - a process Latour calls blackboxing. Next, the authors talk about Einstein:

Based on Planck's idea of quantum, Einstein established that the energy of the incident radiation was concentrated in "particles", which have come to be called photons. He suggested that each photon carries a quantum of energy given by $E=h f$. That is, instead of spreading on the wave fronts, as established by electromagnetic theory, energy is transported in discrete packets. (Bonjorno et al., 2013, p. 248)

In speaking of Einstein, the authors align with his corpuscular view. In doing so, they change the verbal structure they have been using, from modal sentences to past perfect tense and present tense sentences, in a way of strengthening Einstein's view over Planck's (which did not agree with the conception of photon). Still, the verb that the authors use to insert Einstein's speech is quite incisive: they do not claim that Einstein suggested or proposed the photon, but that Einstein "established it" without explaining how it was done. Once again, the dialogism is made through blackboxing. The only mention they make of Einstein's construction is the information that he started from Planck's idea, which is not in accordance with the original article (Einstein, 1905). The association of the concept of photon with Planck's proposal only began one year after his first article (Einstein, 1906) and followed over the subsequent decades. Apparently, the authors adopt this re-reading of Einstein himself and not the version of the original article.

Furthermore, the authors did not care at this point with conciliating the corpuscular aspect of the photon along with the fact that its energy depends on the frequency (wave magnitude). They simply neglected this contradiction. That is, the new Physics is introduced as something that progresses in relation to Classical Physics, but its problems are not discussed. Even though the authors do not make the question of particle-wave conciliation explicit, they do not call photon corpuscles, but "discrete packages", even if the term wave packet appears in Schrödinger's proposal precisely to conciliate a non-relativistic particle that can be localized through its wave nature. That is, the authors seem to perceive the contradiction, but prefer to not to reveal it. This is an indication that the attempt to validate scientific discourse rather than presenting it with its complexity and possible contradictions prevails in didactic discourse.

Following, the authors speak of the Compton Effect: 
Compton understood that both presented similar behavior to what happens when the collision of billiard balls occurs. This can be interpreted as an indication of the X-ray's corpuscular nature. After the shock, the billiard balls remain the same, but in the case of the X-ray experiment, Compton found out that the wavelength of the scattered X-ray is larger than the incident. (Bonjorno et al., 2013, p. 253)

At this moment, the authors present that Compton' proposal is "an indicative of the corpuscular nature", and then enlarge the reliability of his work:

The Compton Effect confirms that photons behave as particles despite their energy being described as a function of the wavelength associated with them - in this case, X-rays. (Bonjorno et al., 2013, p. 253)

What was only a hint in the first part becomes a corroboration in the second. The authors, therefore, continue to reinforce the corpuscular nature of the radiation, interpreting the photon as a particle. To the unwary reader, the text has led so far to the conception that the photon is a particle. Blackboxing prevents the construction of concepts to be known, leaving the reader with no option but to accept the author's ideas. This authoritarian positioning can be perceived in the use of a verb like "to confirm", which carries a strong positivist bias. In the next section, the corpuscular view is again restated:

Phenomena such as the photoelectric effect and the Compton effect have shown that radiation has a corpuscular behavior, since it can be explained with the concept of photon, to which the idea of an amount of energy proportional to the frequency of the emitting source is incorporated. Thus, we can say that electromagnetic radiation consists of a discrete set of energy packets - corpuscles or photons. (Bonjorno et al., 2013, p. 253)

The authors' discourse up to this point expresses a strong essentialist bias towards the corpuscular conception of light, strengthened by a positivist lexical choice. The concept of frequency is assigned to the source emitter (as if it were not property of the particle) - which seems to suggest the end of the conflict. In the following section, however, the authors contrast with what they have discussed:

On the other hand, phenomena such as diffraction and interference, which occur with these radiations, are described theoretically and experimentally by an undulatory nature. (Bonjorno et al., 2013, p. 253)

To that extent, the authors had adopted an essentialist bias to talk about the corpuscles (i.e. light is made up of particles). At that moment, when speaking of the wave phenomena, they call it "description", that is, they portrait the wave conception as an instrumental vision ${ }^{16}$.

In addition, Bonjorno et al. counterpoise the corpuscular view of phenomena related to absorption and emission of photons with effects of light interference and 16 Historically, Physics has its origins associated to an essentialist view, according to which Science discovers which are the essences of reality. The instrumentalist view arises afterwards characterizing Science as an instrument to describe reality, but incapable of discovering its essences (Popper, 2008). 
diffraction. This is Einstein's original conception from 1905, which, as discussed earlier, does not consist of a dual view and therefore is not often referred to as Quantum Physics. The problem of wave-particle duality arises as long as a single photon (whose expected nature would be corpuscular in a common-sense view) presents interference and diffraction of light phenomena. That is, in Quantum Physics, there is no contraposition between macroscopic undulatory vision and microscopic corpuscular vision. In Quantum Physics, there is the duality of corpuscular and undulatory behavior for the same entity, on the same scale. The Copenhagen Interpretation, for example, attempts to explain or resolve such duality and not the conflict between corpuscular photon and continuous radiation. Ignoring this, the authors state:

Therefore, we follow the principle of complementarity, enunciated in 1929 by Niels Bohr, which considers the need for two theories to establish double radiation behavior, although it is never necessary to use both models at the same time to describe certain phenomena. (Bonjorno et al., 2013, p. 254)

The authors, therefore, adopt Einstein's corpuscular view throughout the text and explain the wave behavior of the radiation using the Copenhagen Interpretation (which was not accepted by Einstein) for a problem that is not of Quantum Physics. Thus the view of the authors is a proper interpretation of the nature of light, which corresponds neither to Einstein's view nor to that of Copenhagen, but is a hybridization of these visions ${ }^{17}$. Furthermore, the authors state that

Niels Bohr has accepted the idea that the undulatory and corpuscular behavior of matter and light are two faces of the same basic phenomenon and not two different kinds of events. The undulatory or corpuscular behavior are complementary means of seeing the same phenomenon. It is not the light that changes its characteristics, but the way we decide to interpret it. (Bonjorno et al., 2013, p. 254)

Thus, they present the Complementarity Principle by associating the problems in the description to the theory, adopting an instrumentalist view one more time - which contrasts with the essentialist view adopted in most of the text. The authors state that it is us who decide how to interpret it, which suggests the insertion of a great degree of subjectivity.

Finally, the Bakhtinian analysis of this text allows us to synthesize the following results on the first category:

- The textbook articulates (or dialogues) with the original articles by a process of blackboxing.

- The authors align themselves with a corpuscular voice throughout most of the text. The photon actant presented by the books is very close in terms of its performance to that established by Einstein (early 20th century), as the corpuscular performance of the photon is counterposed to the wave performance of the radiation. That is, for the authors, the single photon does

17 This is also made by the other textbook of this category, except by the books written by Menezes et al (2013) and Sant'Anna et al (2013). 
not exhibit wave behavior in the same way as the Einstein's photon does.

- To explain the photon-radiation dichotomy (different scales), they use the Copenhagen Interpretation, which was not accepted by Einstein and which originally should explain the particle-wave dichotomy for the photon.

- Conclusions ii and iii indicate that, despite dialoguing with the original articles, the authors' view of the photon corresponds neither to Einstein's nor to Copenhagen's view, hybridizing them into a discourse of their own.

- In the process of translation, the intention of the authors can be perceived as that of transmitting the notion of neutral, universal and absolute science - which is reflected in the lexical choice of positivism, in omitting the controversies of interpretation and in the blackboxing process itself. Thus, although these books focus on Basic Education, we can see in them the same didactic ideology of instruction manuals of higher education: to defend a paradigm in an uncritical and instrumentalist way, without worrying about the construction of theories, but only about its application.

- Although they defend a paradigm, the authors' approach does not dialogue with the contemporary conception of Quantum Physics (including the waveparticle duality of the photon), being related only to the theoretical problems of the first two decades of the twentieth century. The paradigm advocated by books has ceased to be hegemonic for more than eight decades by the scientific community.

\section{Texts that explicitly recognize the existence of different interpretations}

In the second category, there are only two books. We present the analysis of the text by Oliveira (2013), as this is the one that presents the longest time interval in the history of electromagnetic radiation, taking up the problem of Newton and Huygens (Lima, Ostermann, \& Cavalcanti, 2017d). If, on the one hand, a presentation with a larger time window is interesting, as it allows the visualization of science in a larger context, on the other hand it means that there was greater suppression of information. This means that the blackboxing process occurs more intensively. Also, the two books in this category adopt the same strategy to carry out the insertion of philosophical interpretations: first, they take a chronological approach as the books of the first category; then they add a text about the Mach Zehnder interferometer and the possible interpretations that it arouses, presenting an approach that was probably inspired by the proposal of Pessoa Jr. (2003).

They narrate the history of light, in the scope of Modern Physics, from the presentation of the Photoelectric Effect according to the classical view of electromagnetic radiation. In the sequence, the authors present a section entitled: "Interpretation of Einstein: light as a particle." The title itself suggests the corpuscular interpretation of radiation, which agrees with what is present in the article and Einstein (1905). The authors assert: 
In 1905, Einstein proposed the theory of the photoelectric effect, which agreed with the experimental results obtained until then and by other researchers with more precise measurements. He stated that the electromagnetic radiation of frequency $\mathrm{f}$ contained "packets" of energy of intensity directly proportional to its frequency. These "packages" were later called photons. (Oliveira et al., 2013, p. 230).

If, in the original articles, the author translated the equations and the phenomena, in the textbook, the author translates the texts of the scientists. This means that its own voice prevails against the scientists' voice. In the section above, Oliveira et al. (2013) call "theory" what Einstein called "hypothesis",and give Einstein's quanta an "energy package" label, a term that may have been imported of Schrödinger's interpretation (which brings the idea of wave packet).

In addition, the authors say that electromagnetic radiation "contained" packages, while the term used by Einstein was "consisting" of quanta. This subtle difference suggests that there is more than packages (perhaps an influence of the dualistic-realistic view, but it is not clear), which does not correspond to Einstein's original view.

These are particles in constant motion which, in vacuum, propagate with velocity of light $c$ and have no mass. We can associate energy $E$ and momentum $Q$ with the photons. (Oliveira et al., 2013, p. 230)

Comparing this section with the previous one, we observe that there is an ontological variation: in the previous section, the authors speak what Einstein thought ("Einstein proposed", "He affirmed that"), but in this passage they are no longer talking about Einstein's vision, but about what reality is ("These are particles"). There was an ontological promotion. Previously the photon was an element of a scientist's speech; now it is already a reality.

In addition, the authors hybridize their current view of the photon with Einstein's original vision, giving it an amount of motion, which Einstein had not done in 1905 . After discussing the Photoelectric Effect, identifying the photon as a particle (and having already discussed wave experiments of radiation), the authors present a section entitled "What is Light After All". The title of the section suggests a strong essentialist bias.

So, with Einstein's corpuscular proposal, should we re-consider the nature of the particulate light? More or less. What we should keep in mind is that we need both representations to deal with the nature of light. In some phenomena, it occurs as a wave, in others as a particle. This is what we refer to in Physics as dual nature of light, or even wave-particle duality. (Oliveira et al., 2013, p. 233)

In this passage, the authors seem to align with the view of Bohr's Complementarity, as they present the existence of two frames that are distinct, but necessary for an explanation of reality. Something important to note is that the whole text is constructed from previous texts (Bakhtin, 2016), and the way they are quoted is closely linked to the speaker's speech project. In the passage above, the corpuscular view is referred to as "Einstein's corpuscular view," but the view of Complementarity is not attributed to 
any author. This suggests, once again, an ontological differentiation: before, we had a proposal; now we have the reality. This "real and true view" is translated once again by an authoritative argument: if the proposition was Einstein's, the vision now is "Physics." Besides being authoritarian, this discourse silences the existence of different interpretations. Proponents of a corpuscular view would not agree with the need for two frames of explanation, but why are they not part of physics? The authors then complete their explanation:

It is important to emphasize that the difficulty in the representation of light is not a problem of the light itself, but of the means that Science and Physics in particular have in describing phenomena and situations. It seems reasonable to assume a dual nature for light. It may present itself as a wave or as a particle, depending on the phenomenon that is being studied and on how the measurement on the object of study is imposed. It is important that the model adapts to the situation, as it is not the light that becomes a particle. (Oliveira et al., 2013, p. 233)

This section has a strong instrumentalist bias, which contradicts the rest of the text and even the title of the section. So far, the authors wanted to explain what light is, now they delegate the problem to the theory. Following, the authors explain Bohr's vision (which had already been published):

The dual nature of light was a direct result of Einstein's proposition on the quantization of electromagnetic radiation and the proposition of the photon. The Danish physicist Niels Bohr (1855-1962) had proposed the principle of Complementarity, considering that light behaves either as a particle or a wave. Never as both simultaneously. (Oliveira et al., 2013, p. 234)

In saying this, the authors suppress an important discussion: Einstein's view in 1905 was not dual (Martins, \& Rosa, 2014) - Einstein's view was "classical" - radiation was composed of particles. The duality appears structured only in a theoretical proposal in De Broglie (Martins, \& Rosa, 2014). This, once again, exemplifies a translation of history in which subsequent visions are preferable upon the original vision. In the sequence, another instrumentalist passage:

In this sense, the wave-particle duality and the issue about the relativity of space and time serve as a warning to the limits of our intellect in dealing with the complexity of nature beyond the everyday world. (Oliveira et al., 2013, p. 234)

This is again a statement that opposes to the essentialist view of the rest of the text. According to it, the results of a physical theory give us information about the human intellect and not about reality - which implies, in addition to instrumentalism, idealism (Physics would not speak of reality, but of knowledge). This statement is unexpected, as the first author of the book has published articles in which he suggests the implementation of Mario Bunge's Epistemology in Teaching Physics (Pietrocola, 1999), which is explicitly against such kind of interpretation of physical theories (Bunge, 2013) . In the same section, the authors insert a textbox called "Exploring the situation" in 
which they present the Mach-Zehnder Interferometer in classical and quantum versions and the following excerpt:

Thus, as in the case of the monochromatic light beam, the photon does not reach the detector D2. Assuming that the photon is in A, we can remove the semi-reflective glass $\mathrm{S} 1$, assuming it is in $\mathrm{B}$, replace the semi-reflective glass $\mathrm{S} 1$ with a mirror. In any of the experiments, it reaches detector D1. As the photon is a particle, how is that possible? (...) This result can have four interpretations: wave, corpuscular, dualistic realist and complementarity. According to the wave interpretation, a photon is a "wave packet" which may, in S1, be divided into two "half-photons", which recombine in S2. However, no half photon has yet been detected. (Oliveira et al., 2013, p. 234)

The authors are using a group of classifications for philosophical interpretations of the photon probably inspired by Pessoa Jr. (2003). On the corpuscular interpretation, the authors affirm:

In the corpuscular interpretation, in which the photon is a particle, there is no good explanation for the phenomenon observed. One can try to justify by saying that the logic of the quantum world is different from the macroscopic world and the photon can be and not be a particle at the same time. (Oliveira et al., 2013, p. 235)

After saying that the corpuscular interpretation portraits the photon as a particle, the author says that the explanation about this view is that the photon may not be a particle, which is not in line with the original text of Pessoa Jr (2003). According to this interpretation, the photon is a particle, but it may or may not be in two different paths.

Originally formulated by Louis de Broglie and rediscovered by David Bohm, the dualistic realist interpretation explains that light is divided into two parts: a particle and a wave, with the position of the particle depending on the frequency of the wave.

(Oliveira et al., 2013, p. 235)

In this section, the authors present a proposition that is inconsistent with Born's interpretation, according to which the most probable position of the particle depends on the amplitude of the wave function and not its frequency. Finally, the authors explain the vision of complementarity:

According to the interpretation proposed by Niels Bohr, that of complementarity, light can be either wave or particle, never both at the same time. Thus, the result of this experiment indicates an undulating phenomenon, in which light does not follow a welldefined path. So it does not make sense to ask where the photon is. (Oliveira et al., 2013, p. 235).

In general, we can summarize that the texts that present the interpretations of the photon explicitly have the following characteristics:

- The introduction of the interpretations shows up at the end of the text and does not dialogue with the rest of the chapter. In other words, the student is exposed to an inconsistent ontological and epistemological text and, in the end, is introduced to the interpretations of the photon, which had already 
been used in an uncritical way. If the authors themselves failed to use the photon interpretation groups to think about their didactic output, what to expect from the students' learning?

- Throughout the narrative, the authors alternate between telling the "scientist" view and the "reality" view. This is done discursively by explicitly explaining and omitting the references.

- The authors superimpose the view of different interpretations in the same view like the books of the first group.

\section{The textbook adheres to a specific interpretation and argues it is the only possibility}

The only text that adheres only to the corpuscular view of light is contained in Gaspar's (2013) book:

In summary, according to Einstein, light, like any electromagnetic radiation, does not propagate uniformly through space as suggested by the wave theory, but by means of corpuscles, or quanta of light, later called photons. (...) the photons are like packets of energy $(E)$ proportional to the frequency $(f)$ of the radiation. (Gaspar, 2013, p. 210)

Such discourse, like the present in other cases, has an authoritarian bias: Gaspar (2013) does not present the construction of the photon; he simply informs the student that the light is made by corpuscles. But if it is composed of corpuscles, what is the sense of frequency? The author does not explain. The only way to convince the reader is through an authoritative argument:

Therefore, there are those who say that light has a dualistic character - it behaves wither as a particle or as a wave (...). In fact, this statement is not correct: the alternative duality, being one thing or another, does not exist. For present physics, there is no doubt that a beam of light is a beam of particles, that is, a bundle of photons. Duality arises in relation to the collective behavior of this beam, which is undulatory. (Gaspar, 2013, p. 214)

The author uses the stylistic feature of opposing the dual vision of light, using the expression "there are those who say", with the corpuscular view: "Actually", "for present physics", "there is no doubt". That is, according to Gaspar (2013), there are those who say that light has dual behavior, while "in fact", in current physics, "there is no doubt" that the light is corpuscular. If the student had been confused about the nature of the light, he could not stay any longer. The author explicitly adheres to the vision of Statistical Ensembles (Ballentine, 1970) and forcibly silence the other views. Next, he talks about the double-slot experiment for the photon:

This result, surprising up to this day, has been misunderstood for some time, until the middle of the twentieth century. This is because this figure, according to the wave theory, is only possible when waves from two different sources reach the same point at the same time and interfere with each other. So some physicists concluded that for such a figure to form with particles - individual photons going through the slits -, 
each photon would have to interfere with itself. Each photon would cross the two slits simultaneously, and then it would recompose itself again, reestablishing its unity, but with a new character, due to its self-interference. In this case, we might conclude that a particle can be in two places at the same time, which would have extraordinary physical and philosophical implications. (Gaspar, 2013, p. 216)

And continues:

But this is not what happens. The sequence of figures shows that the photons reach the photographic plate individually. In addition, there is experimental evidence to prove that this division, or ability to be in two places at the same time, does not occur. Each photon passes through only one slit at a time. But why does the figure have wave characteristics if it is formed by particles? The answer to this question lies on the behavior of nature in the microcosm, which cannot be extrapolated from the behavior of macroscopic particles - photons are not rigid balls like hunting pellets, as has already been said. This, incidentally, is one of the main conclusions of modern physics. The description of the behavior of the photons is already known. The way photons interact with matter is perfectly determined by means of a probability calculus that has yielded extraordinarily accurate results from a new theory of modern physics - Quantum Electrodynamics. (Gaspar, 2013, p. 218)

To justify the corpuscular behavior, the author points out that "there is experimental evidence" that the photon cannot be divided, without specifying them. In addition, he claims that Quantum Electrodynamics is responsible for explaining the problem. Namely, the author ends the discussion. The student has no explanation of how this should be understood; he just needs to accept it. The "explanation" is given by linguistic articulation with the argument of authority. This leads to the last result:

- The text that omits not only the existence of interpretations, but also the controversies, adhering to one single interpretation, has to be much more authoritarian than the other texts. The text of Gaspar (2013) is stylistically highlighted by discursive impositions of what he does not propose to justify intellectually.

\section{Final considerations}

In this work, we presented a study of Symmetric Sociology of Science Education, articulating the Symmetric Sociology of Bruno Latour and the Philosophy of Language of Mikhail Bakhtin. In doing so, we chose to describe the processes of dialogism and translation existing in different scientific and didactic texts, rather than seeking the traditional dichotomy of history versus pseudo-history.

This theoretical articulation made it possible to discuss something unheard of, namely, that the style of the quoted discourse (a fundamental issue according to Bakhtin's philosophy) in textbooks is closely associated with the stabilization of the essence of the photon (an element of nature) and the relation between basic education and science education (a social issue). In other words, we relate, in a single analysis, 
language, nature and society (Latour's methodological proposal). In order to achieve this goal, we approach the concept of translation by Latour with the concept of dialogism by Bakhtin. Such a proposal, in itself, is a translation of the original ideas. To do so, we need to extend Latour's research project, which never focused on Science Education, and the scope of Bakhtin's (human-driven) work to incorporate the "speech" of nonhuman actants. That is, we extrapolate the research contexts of each author to discuss the hybrid nature of Science Education. With this, we symmetry not only truth and falsehood and human and non-human, as proposed by Latour, but also the genre of scientific and didactic discourse. The approach taken in this work, using the concepts of translation and dialogism, is not the only one possible. We hope that it will motivate future articulations between the works of these authors, for the reason that this will allow the proposition of a sociological view of Science Education and its relations with nature and society, which we call Symmetrical Sociology of Science Education.

After carrying out a theoretical and methodological reflection, we present a possible history of the photon in which the different interpretations appear as translation processes. Thus, we show that, in the context of scientific texts, worldviews are reflected and refracted by texts in a dialogical way.

Textbooks, on the other hand, belong to another genre of discourse, which dialogues with the scientific genre. Each textbook, therefore, also reflects and refracts characteristics of the original articles in a way that it is never a faithful copy of the original text, nor it is fully comparable to it. We present in this article how textbooks dialogue with the original articles and how the style (lexical and grammatical choices) modulates the truth value that the author of the text intends to print.

In general, we identified three styles of approach of quoted discourse: there are texts that use the interpretations of the photon without explicitly saying that there are different interpretations (a group with 11 books); there are texts that explain the existence of different interpretations of the photon (group with 2 books); and there is text that takes only one interpretation. The metalinguistic analysis of the books that were put in the first category indicates that they translate the original articles through blackboxing processes, omitting the construction of the photon and suppressing theoretical discussions. The presentation of the photon is made by hybridizing different positions adopted during the first decades of the twentieth century in a completely new vision. The authors, in line with Einstein's view, understand that the photon is a particle (microscopic scale); and, in line with Schrödinger's view, understand that the radiation is a wave (macroscopic scale). Finally, they use the Copenhagen Interpretation to explain this duality at different scales, though the original interpretation would explain the duality of the photon (a single scale).

With the performances revealed by the authors of the first group, the photon actant is a classical particle and would not be considered object of study of the Quantum Physics (contemporary), as it does not present wave-particle duality in the same scale. In addition, we identified that, in these narratives, the authors vary between an 
ontological and an epistemological bias regarding the photon, associating it to either an essential or an instrumental trait. This may create complications in understanding the concept of photon that could be avoided if the authors exposed the existence of different interpretations and discussed each experimental arrangement in the light of such conceptual plurality.

The fact that the authors endorse an instrumentalist didactic view (which simply presents concepts to be used in problem solving) rather than discussing the theoretical and experimental constructions of photon, with its limitations and controversies, reveals that they follow the same didactic perspective revealed by Kuhn in the context of the development of scientists: the controversies are hidden, the theoretical bases are omitted, and solving puzzles of a paradigm become the only preparation. The question that should be asked is: does it make sense to adopt textbooks that follow the same ideological orientation of higher education books? Do we want to form high school students as small scientists, capable of inserting formulas into problems, but incapable of understanding the limitations of their own theories? We understand that if, in fact, we aim for a critical education, which would be the basis of citizenship, the didactic model of science is unacceptable, as it is alienating not only from a political point of view, but also from an educational one.

The high amounts invested by the government in the National Plan of Textbooks, combined with the low training of the authors of these books, result in texts didactically colonized from a structural point of view (Lima, Ostermann, \& Cavalcanti, 2017) and didactically ideological. Furthermore, in spite of being scientific, the vision of photon present in the textbooks circumscribes to the description of the photon from the 1920s, having little link with the contemporary literature. Namely, even if the goal was to form a small scientist, their vision would be dissonant with the vision of the current paradigm! Textbooks are preparing students for a paradigm that has already been abandoned. Thus, a rationality of its own is created, which is based only on the authoritarian narrative of the books, or, as Alice Lopes would say, a "accommodated and conformist reason, the rationalism with school taste, the way school has done, as cheerful as the gates of a prison"(Lopes, 1996, p.270).

The texts that were put in the second and third categories present the same didactic problems of the first one. The metalinguistic analysis of the books from the second category, for example, points out that they follow a similar approach to the texts of the first group, but add a text on the interpretations of photon, at the end of the chapter, which dialogues the least with the rest of the text.

When compared to the first group, the texts in this category amplify the photon performances as they explicitly discuss their wave-particle duality. Nevertheless, the discursive strategy of adding a text to the end of a section rather than presenting controversies regarding the subject can again be problematic from a didactic point of view. It makes no sense to make explicit the multiplicity of interpretations of the photon after a whole text that omits it. It is difficult for the reader to articulate these ideas with 
the rest of what they have read. By the way, the lack of cohesion of the text suggests that the authors themselves do not even understand the interpretations of photon, but added them to be in consonance with the literature on Teaching of Quantum Physics. Finally, the text of the last group not only does not explain the existence of different interpretations but denies the legitimacy of different views, stating that the corpuscular view is the only correct. Our analysis indicates that this is the most authoritarian approach of the three, presenting stylistic features to suppress the existence of controversies.

While forming a physicist demands for him to learn to substitute values in equations whose meaning, construction, and implications mean anything to him (an issue that must be addressed) (Johansson, Andersson, Salminen-Karlsson, \& Elmgren, 2016), forming a citizen takes much more than that. We cannot simply copy the baccalaureate model for high school simply by deleting the derivatives and integrals. It is possible to teach science and, more specifically, Quantum Physics, by discussing its theoretical and philosophical bases in line with contemporary literature, as has been done in books and research on Science Education at least in high education contexts (Betz, 2014; Montenegro, \& Pessoa Jr., 2002; Netto, Cavalcanti, \& Ostermann, 2015; Netto, Ostermann, \& Prado, 2011; Pereira \& Ostermann, 2012; Pereira, Ostermann, \& Cavalcanti, 2009; Pereira, Ostermann, \& Cavalcanti, 2012; Pessoa Jr., 2003). For critical proposals to be implemented in Basic Education, more works are necessary from a symmetrical sociological point of view, without falling to the dichotomy of history or pseudohistory when investigating the relations between didactic and scientific productions. From these studies, we hope that the area of Science Education will acquire more subsidies to think about a didactic construction for basic education with its own identity, without having to position itself subserviently to other communities.

\section{References}

Allchin, D. (2004). Pseudohistory and Pseudoscience. Science \& Education, 13(3), 179195.

Aquino, T. (1995). O Ente e a Essência. Porto: Edições Contraponto.

Artuso, A. R., \& Wrublewski, M. (2013). Física. Curitiba: Positivo.

Bakhtin, M. (1981). The Dialogic Imagination. Austin: University of Texas.

Bakhtin, M. (1984a). Problems of Dostoyevsky's Poetics. Minneapolis: University of Minnesota Press.

Bakhtin, M. (1984b). Rabelais and His World. Bloomington: Indiana University Press.

Bakhtin, M. (1997). A Estética da Criação Verbal (2 ed.). São Paulo: Martins Fontes.

Bakhtin, M. (2006). Marxismo e Filosofia da Linguagem (12 ed.). São Paulo: HUCITEC.

Bakhtin, M. (2016). Os Gêneros do Discurso. São Paulo: Editora 34. 
Bakhtin, M. (2017). Notas sobre Literatura, Cutura e Ciências Humanas. São Paulo: Editora 34.

Ballentine, L. E. (1970). The Statistical Interpretation of Quantum Mechanics. Reviews of Modern Physics, 42(4), 358-381. https://doi.org/10.1103/RevModPhys.42.358

Barreto, B., \& Xavier, C. (2013). Física Aula por Aula (2 ed. Vol. 3). São Paulo: FTD.

Betz, M. E. M. (2014). Elementos de mecânica quântica da partícula na interpretação ao da onda piloto. Revista Brasileira de Ensino de Física, 36(4), 1-14.

Bialynicki-Birula, I. (1994). On the wave function of the photon. Acta Physica Polonica Series A, 86(1-2), 97-116.

Bialynicki-Birula, I. (1996). The photon wave function. In J. H. Eberly, L. Mandel, \& E. Wolf (Eds.), Coherence and quantum optics VII (pp. 313-322). Boston, MA: Springer US. Recuperado de https://link.springer.com/chapter/ 10.1007/978-1-4757-9742-8_38

Bloor, D. (1982). Sociologie de la logique ou es limites de l'épistemoogie. Paris: Éditions Pandora.

Bohr, N. (1928). The Quantum Postulate and the Recent Development of Atomic Theory. Nature, 121, 580-590.

Bonjorno, J. R., Clinton, M. R., Prado, E., Casemiro, R., \& Bonjorno, R. A. (2013). Física (2 ed. Vol. 3). São Paulo: FTD.

Born, M. (1926). Zur Quantenmechanik der Stoßvorgänge. Zeitschrift fur Physik, 37, 863-867.

Brush, S. G. (1974). Should the History of Science Be Rated X? The way scientists behave (according to historians) might not be a good model for students. Nature, 183(4130), 1164-1172. https://doi.org/10.1126/science.183.4130.1164

Bunge, M. (2013). Física e Filosofia. São Paulo: Perspectiva.

Callon, M. (1986). Éléments por une Sociologie de la Traduction: La domestication des coquiles Saint-Jacques et e marins-pêcheurs dans a baie Saint-Brieuc. L'Année Sociologique, 36, 169-208.

Compton, A. H. (1923). A Quantum Theory of the Scattering of X-rays by Light Elements. Physical Review, 21(5), 483-502. https://doi.org/10.1103/PhysRev.21.483

De Broglie, L. (1922). Rayonnement noir et quanta de lumière. Le Journal de Physique et le Radium, 3(6), 422-428.

De Broglie, L. (1923). Ondes et quanta. Comptes Rendus de l'Académie des Sciences de Paris, 117, 507-510.

Doca, R. H., Bôas, N. V., \& Biscuola, G. J. (2013). Fisica (Vol. 3). São Paulo: Saraiva. 
Einstein, A. (1905). Über einen die Erzeugung und Verwandlung des Lichtes betreffenden heuristischen Gesichtspunkt. Annalen der Physik, 17, 132-148.

Einstein, A. (1906). Die Plancksche Theorie der Strahlung und die Lichtquantem. Annalen der Physik, 20, 199-206.

Feyerabend, P. (2011). Contra o Método (2 ed.). São Paulo: Unesp.

Johansson, A., Andersson, S., Salminen-Karlsson, M., \& Elmgren, M. (2016). "Shut up and calculate": the available discursive positions in quantum physics courses. Cultural Studies of Science Education, 1-22. https://doi.org/10.1007/s11422-016-9742-8

Garcia, N. M. D. (2017). O Livro Didático de Física e de Ciências em foco: Dez Anos de Pesquisa. São Paulo: Editora Livraria da Física.

Gaspar, A. (2013). Compreendendo a Física volume 3 (2 ed.). São Paulo: Ática.

Gonçalves Filho, A., \& Toscano, C. (2013). Física: Interação e Tecnologia (Vol. 3). São Paulo: Leya.

Greenstein, G., \& Zajonc, A. G. (1997). The Quantum Challange: Modern Research on the Foundations of Quantum Mechanics. Sudbury: Jones and Bartlett Publishers.

Guimarães, O., Piqueira, J. R., \& Carron, W. (2013). Física (Vol. 3). São Paulo: Ática.

Jammer, M. (1974). The Philosophy of Quantum Mechanics. New York: John Wiley and Sons.

Kincheloe, J. L., \& Tobin, K. (2009). The much exaggerated death of positivism. Cultural Studies of Science Education, 4 (3), 513-528. doi: 10.1007/s11422-009-9178-5

Kuhn, T. (1978). A Estrutura das Revoluções Científicas. São Paulo: Perspectiva.

Latour, B. (1988). A Relativistic Account of Einstein's Relativity. Social Studies of Science, 18(1), 3-44.

Latour, B. (1999). Pandoras Hope - Essays on the Reality of Science Studies. Cambridge: Harvard University Press.

Latour, B. (2011). Ciência em ação: como seguir cientistas e engenheiros sociedade afora (2 ed.). São Paulo: Unesp.

Latour, B. (2013). Jamais Fomos Modernos (3 ed.). São Paulo: Editora 34.

Latour, B., \& Fabbri, P. (1977). La rhétorique de la science. Actes de la recherche en sciences sociales, 13(1), 81-95. https://doi.org/10.3406/arss.1977.3496

Latour, B., \& Woolgar, S. (1988). La vie de laboratoire: la Production des faits scientifiques. Paris: La Découverte.

Latour, B., \& Woolgar, S. (1997). A vida de laboratório: a produção dos fatos científicos. Rio de Janeiro: Relume Dumará. 
Lima, N. W., Antunes, E., Ostermann, F., \& Cavalcanti, C. (2017a). A História do Fóton em Livros de Física. Enseñanza de las Ciencias, extra, 1953-1957.

Lima, N. W., Antunes, E., Ostermann, F., \& Cavalcanti, C. (2017b). Interpretações do Fóton em Livros Didáticos do Ensino Superior. Trabalho apresentado em XI Encontro Nacional de Pesquisa em Educação em Ciências, Florianópolis.

Lima, N. W., Antunes, E., Ostermann, F., \& Cavalcanti, C. (2017c). Uma Análise Bakhtiniana dos Enunciados Sobre o Efeito Fotoelétrico em Livros Didáticos do Ensino Superior. Enseñanza de las Ciencias, extra, 1947-1951.

Lima, N. W., Ostermann, F., \& Cavalcanti, C. (2017). Física Quântica no ensino médio: uma análise bakhtiniana de enunciados em livros didáticos de Física aprovados no PNLDEM2015. Caderno Brasileiro de Ensino de Física, 34(2), 435-459.

Lopes, A. R. C. (1996). Bachelard: o Filósofo da Desilusão. Caderno Brasileiro de Ensino de Física, 13(3), 248-273.

Luz, A. M. R. D., \& Álvares, M. A. (2013). Física Contexto \& Aplicações (Vol. 3). São Paulo: Scipione.

Martins, R. d. A., \& Rosa, P. S. (2014). História da teoria quântica - a dualidade ondapartícula, de Einstein a De Broglie. São Paulo: Livraria da Física.

Menezes, L. C. d., Canto Júmior, O., Kantor, C. A., Paoliello Júnior, L. A., Bonetti, M. d. C., \& Alves, V. M. (2013). Quanta Física (Vol. 3). São Paulo: Pearson Education do Brasil.

Ministério da Educação. (2014). Guia de livros didáticos: PNLD 2015: física: ensino médio. Brasília: Autor.

Montenegro, R. L., \& Pessoa Jr., O. (2002). Interpretações da teoria quântica e as concepções dos alunos do curso de física. Investigações em Ensino de Ciências, 7(2), 107-126.

Nelson, M. (2012). Existence. Recuperado de https://plato.stanford.edu/entries/ existence/

Netto, J. S., Cavalcanti, C., \& Ostermann, F. (2015). Estratégias discursivas adotadas por professores em formação na compreensão do fenômeno da complementaridade em atividades didáticas mediadas pelo interferômetro virtual de Mach-Zehnder. Revista Brasileira de Pesquisa em Educação em Ciências, 15(2), 293-320.

Netto, J. S., Ostermann, F., \& Prado, S. (2011). O tema da dualidade onda-partícula na educação profissional em radiologia médica a partir da simulação do Interferômetro de Mach-Zehnder. Revista Brasileira de Ensino de Física, 33(1), 1-10.

Oliveira, M. P. P., Progibin, A., Andrade, R., \& Romero, T. R. (2013). Física: conceitos e contextos: pessoal, social e histórico, eletricidade e magnetismo, ondas eletromagnéticas, radiação e matéria. São Paulo: FTD. 
Ostermann, F., \& Moreira, M. A. (2000). Uma revisão bibliográfica sobre a área de pesquisa "física moderna e contemporânea no ensino médio". Investigações em Ensino de Ciências, 5(1), 23-48.

Pereira, A., \& Ostermann, F. (2012). Recursos e Restrições nas Explicações de Futuros Professores de Física sobre Mecânica Quântica. Revista Brasileira de Pesquisa em Educação em Ciências, 12(2), 9-28.

Pereira, A., Ostermann, F., \& Cavalcanti, C. (2009). On the use of a virtual Mach-Zehnder interferometer in the teaching of quantum mechanics. Physics Education, 44(3), 281291.

Pereira, A. P., Ostermann, F., \& Cavalcanti, C. J. H. (2012). Um exemplo de "distribuição social da mente" em uma aula de física quântica. Ciência \& Educação, 18(2), 257-270.

Pessoa Jr., O. (2003). Conceito de Física Quântica. São Paulo: Livraria da Física.

Piassi, L. P., Santos, E. I. d., Vieira, R. M. d. B., \& Ferreira, N. C. (2009). O discurso ideológico sobre Aristóteles nos livros didáticos de Física. Revista Brasileira de Pesquisa em Educação em Ciências, 9(2), 1-19.

Pietrocola, M. (1999). Construção e realidade: o realismo científico de mário bunge e o ensino de ciências através de modelos. Investigações em Ensino de Ciências, 4 (3), 213-227.

Popper, K. R. (1957). The Propensity Interpretation of the Calculus of Probability, and the Quantum Theory. In S. Körner (Ed.), Observation and Interpretation (pp. 65-70): Butterworths.

Sant’Anna, B., Martini, G., Spinelli, W., \& Reis, H. C. (2013). Conexões com a Física (2 ed. Vol. 3). São Paulo: Moderna.

Sartre, J. P. (2007). Existentialism is a Humanism. New Haven: Yale University Press.

Schrodinger, E. (1927). Über den Comptoneffekt. Annalen der Physik, 4 (82), 257-264.

Schrodinger, E. (1928). Collected Papers on Wave Mechanics London and Glasgow: Backie \& Son Limited.

Siegel, H. (1979). On the Distortion of the History of Science in Science Education. Science Education, 63(1), 111-118.

Silva, A. C., \& Almeida, M. J. P. M. (2011). Física quântica no ensino médio: o que dizem as pesquisas. Caderno Brasileiro de Ensino de Física, 28(3), 624-652. https://doi. org/10.5007/2175-7941.2011v28n3p624

Silveira, F. L. (2002). A Premissa Metafísica da Revolução Copernicana. Caderno Brasileiro de Ensino de Física, 19(1), 407-410. 
Silveira, F. L., \& Ostermann, F. (2002). A insustentabilidade da proposta indutivista de "descobrir a lei a partir de resultados experimentais". Caderno Brasileiro de Ensino de Física, 19(número especial), 7-27.

Stefanovits, A. (Editor responsável) (2013). Ser protagonista: Física. $1^{\circ}$ ano: ensino médio (2 ed.) São Paulo: Edições SM.

Torres, C. M. A., Ferraro, N. G., Soares, P. A. d. T., \& Penteado, P. C. M. (2013). Física Ciência e Tecnologia (3 ed.). São Paulo: Moderna.

Veneu, A., Ferraz, G., \& Rezende, F. (2015). Análise De Discursos No Ensino De Ciências: Considerações Teóricas, Implicações Epistemológicas E Metodológicas. Ensaio Pesquisa em Educação em Ciências, 17(1), 126-149. https://doi.org/10.1590/1983211720175170106

Voloshinov, V. N. (1981). La structure de l'enoncé. In T. Todorov, Mikhaïl Bakhtine: le principe dialogique (pp. 278-316). Paris: Seuil.

Wertsch, J. (1992). Voices of the mind: a sociocultural approach to mediated action. Cambridge: Harvard University Press.

Wertsch, J. (2004). Voices of Collective Remembering. Cambridge: Cambridge University Press.

Yamamoto, K., \& Fuke, L. F. (2013). Física para o Ensino Médio 3 (3 ed.). São Paulo: Saraiva. 
Nathan Willig Lima

${ }^{\circ}$ http://orcid.org/0000-0002-0566-3968 Universidade Federal do Rio Grande do Sul Instituto de Física Porto Alegre, Brazil 00182656@ufrgs.br

\section{Bruno Birkheur de Souza}

(1) http://orcid.org/0000-0001-8165-5807 Universidade Federal do Rio Grande do Sul Instituto de Física Porto Alegre, Brazil bruno.fonini@hotmail.com

\section{Fernanda Ostermann}

(ㄷ) http://orcid.org/0000-0002-0594-2174 Universidade Federal do Rio Grande do Sul Instituto de Física Porto Alegre, Brazil 00008943@ufrgs.br

Claudio José de Holanda Cavalcanti

(1) http://orcid.org/0000-0002-2477-3150 Universidade Federal do Rio Grande do Sul Instituto de Física Porto Alegre, Brazil claudio.cavalcanti@ufrgs.br

Submitted on 1st March 2018 Accepted on 17th March 2018 Published on 27th April 2018 